\title{
Influence of assortment allocation management in the warehouse on the human workload
}

\author{
I. Kudelska ${ }^{1}$ (D) G. Pawłowski ${ }^{2}$
}

Published online: 11 May 2019

(C) The Author(s) 2019

\begin{abstract}
Activities related to allocation of goods in the warehouse are crucial for logistics. All operations with goods in the warehousing area are labour-intensive and time-consuming, which in turn generates warehousing costs. Despite the ongoing automation in this area, human labour is still applicable in many warehouses. This study includes researches on impact of the assortment allocation in the warehouse on the human factor (HR). It includes the analysis for research literature concerning the warehousing and picking influence on HR in its scope, as well as simulation of goods allocation in the warehousing area and discussion concerning the obtained results. The simulation is carried out with application of the swarm algorithm, and the results were subjected to the statistical analysis. Correlation of cost optimization and factors influencing the ergonomics of operation in the warehousing area is determined.
\end{abstract}

Keywords Human factor - Warehousing · Products location - Warehouse costs · Swarm algorithms

\section{Introduction}

People are crucial part in the company. They participate in assembly, transport, manufacturing, warehousing, use, maintenance and disassembly. They are the resources of every designed and created system. However, according to Glock et al. (2017), HF are scarcely involved in the engineering studies.

I. Kudelska

izabela.kudelska@put.poznan.pl

G. Pawłowski

grzegorz.pawlowski@wsb.poznan.pl

1 Faculty of Engineering Management, Poznan University of Technology, Strzelecka 11, 60-965 Poznan, Poland

2 Faculty of Finance and Banking, WSB University in Poznan, Powstańców Wielkopolskich 5, 61-895 Poznan, Poland 
The existing interactions between a human and the created industrial system (Jasiulewicz-Kaczmarek and Saniuk 2015), particularly the warehousing system, may be or are a technical problem. They are mainly related to the efficiency and effectiveness of processes occurring in the warehousing system, which is characterized with large amount of manual human labour (Grosse et al. 2015).

Warehouses are important points in every company and supply chain. Due to the consumption of labour and time, the picking process is widely taken into account. This process can account for over 50\% of warehouse operational costs (Grosse et al. 2015; Frazelle 2002). Automation at warehouses allows for optimisation of processes in many companies, but in most companies manual operations are still applicable, as it is demonstrated in the latest DHL report (Report DHL 2018).

When personnel costs constitute the general cost for majority of warehouse operations, two surprising statistics were included in the DHL report, namely only 5\% of current warehouses are fully automated, and $80 \%$ were manually operated without any automation support (Report DHL 2018; Report Automation in warehouse 2018). Similar studies were also carried out by Baker and Perotti (2008), as well as Napolitano (2012).

The Robotics in Logistics report (Report DHL 2018) stated, that the warehouses increased efficiency and capacity when the work of the warehouses worker was supported by a good warehouse layout design, mobile reloading devices and constant improvement in the IT infrastructure. It was found, that "even in the most automated environments, people still had to be employed at key functions" (Report Automation in warehouse 2018). Large sorting centres are the example, where even more than 1000 employees can still pursue operations such as loading and unloading of transport, manual sorting of objects with unusual sizes. Slow pace is the effect of traditional organizational change scenarios (Report Automation in warehouse 2018).

In addition, people are more flexible than machines and react faster to unexpected changes in the warehousing process, particularly when a change requires logical justification (Grosse et al. 2015). This is confirmed by the researchers presented by De Koster et al. (2007), who suggested that more than $80 \%$ of labour is done manually (Grosse et al. 2015). In turn, high flexibility of warehouse employees leads to high labour costs, what makes that the picking process is expensive and time-consuming (Tompkins et al. 2010; Richards 2014).

In the warehousing process, many activities are made manually. A traditional warehouseman usually spends majority of own time at walking around the warehouse or such a person occupies sitting position and drives the means of internal transport. When moving in the warehouse, such a worker can make up to $25 \mathrm{~km}$ during a single shift (Report Automatization in warehouse 2018).

With an aging European society (e.g. in Poland) we should be aware, that few employees are willing or capable to perform such works at the age of sixty. Apart from that, labour in the warehouse is not homogeneous. Threats related to the warehouseman's operation are significantly related to the stored goods and storage conditions. The most important risks resulting from labour in the warehouse are: mechanical injuries, overloading of the motoric system, usually arising from a position on a trolley or a lift chair, musculoskeletal diseases, a psychological stress often caused by working conditions, such as lighting, noise or pressure exerted by superiors. The pro- 
fession of a warehouse worker is difficult job and the presented threats comprise only a selection of the most common risks.

In order to demonstrate the actual scale of accidents at work in the analysed industry, the researches made for the Polish Social Insurance Institution (pol. Zakład Ubezpieczeń Społecznych - ZUS) and data from the Central Statistical Office (Statistics Poland (GUS)) were used. According to the studies conducted in Poland in the first half of 2018, the number of people injured during the accidents at work amounted to 3193 , in total, and although it is smaller than last year, it is still high when compared to other industries. For example, in the construction industry, the number of people injured in accidents at work amounted to 2226 in the same period, whereas in the mining and extractive industries it amounted to 981 . With breaking down into the economic activities in Poland, the accident rate was one of the highest and it was at the level of 3.72, which means that in the sections of the Polish Classification of Activities (pol. Polska Klasyfikacja Działalności-PKD) transport and warehousing industry occupied the fifth place, in terms of the number of victims per 1000 workers (Statistics Poland (GUS)).

The current statistical data presented above confirms that the human factor problem in the warehousing industry is important and up-to-date. In addition, in the papers of Grosse et al. (2015) it is also emphasized, that the role of human factor in designing the process is often ignored for benefit of management. Researchers and scientists are focused on developing decision-supporting models, that primarily provide aid in the achievement of economic efficiency goals, such as low costs, what was highlighted in the papers of Grosse et al. (2017), and in the papers of De Koster et al. (2007), without paying attention to the system design, in terms of human-system and system-human relations.

This study has the following structure. Section 2 illustrates the research methodology and the problematic context, with main assumptions. Section 3 is analysis for available scientific literature in terms of warehousing, with particular focus on warehousing and human factor. Section 4 is a model and analysis for obtained results. This study is ended up with Sect. 5, where conclusions are presented.

\section{Research problem}

Due to the relation between the ergonomic aspects and the effectiveness of warehousing, several authors made researches on incorporating the ergonomics elements in the decision-supporting model, in the scope of picking process (Boysen et al. 2015; Grosse et al. 2015). In order to supplement the above research gap, authors of this study focused on studying the human-system relation, with respect to allocation of goods.

The warehousing process is important, because of i.e. the function of establishing applicability of time. In other words, in the warehousing area goods should be stored at such time and in such a location, where they are needed by recipients for provision of the demanded customer service level. The pursued activities are primarily transport and handling, that have a significant impact on the warehousing cost. In addition, the 
allocation method has also impact on the picking process, thus the researches in this respect are included in the literature analysis.

Therefore, allocation of goods in the warehouse, where the goods are located, presents the research concern. Analysis for allocation, with regard to HR, is the purpose of analysis. In order to reach the primary goal, it was decomposed into detailed goals:

- DG1: literature analysis for the subject, referring to HR

- DG2: constructing the simulation model

- DG3: analysis for results obtained from the conducted simulation

On the basis of the presented research goal, the following research question was formulated:

- RQ1: is the optimal configuration for a goods allocation the best, when focusing on labor intensity of a warehouseman?

- RQ2: how the logistic factors for efficiency of a warehouseman look like?

\section{A literature review}

In recent decades literature on the warehouse management has been widely discussed in many prestigious scientific journals. According to studies by Grosse et al. (2017), the largest number of papers was noted in the Journal of Production Research, where 30 documents were published. Whereas, this subject was also discussed in the following journals: European Journal Operational Research, IIE Transactions, Computers \& Industrial Engineering. Problems in the papers referred above were generally related to designing and management researches in the field of picking.

A typical approach to planning (e.g. grouping of orders, routes) in the picking process was presented by Van den Berg (1999). The warehouse designing and control aspects at the strategic, tactical and operational level were presented by Rouwenhorst et al. (2000). Authors demonstrated, that warehouse efficiency is the maximum throughput with minimal investment and operational costs. However, environmental and ergonomic aspects, although very important, are difficult in the assessment (Grosse et al. 2017). Pervin et al. (2018) developed recently a deterministic inventory control model with deterioration.

A wide review and assessment for processes in the picking area, including allocation of routes, is presented by $\mathrm{Gu}$ et al. (2007), (2010). An approach to planning, that can provide efficient management for warehousing processes, is presented by De Koster et al. (2007).

Stochastic models for warehouse operations were provided by Gong and de Koster (2011). In the studies they demonstrated that employees may be inaccurate or may make mistakes in the picking phase. The main reason for such a state is absenteeism or longer sick leaves.

Staudt et al. (2015) studied the performance measurement factors in the warehouse. In the study they demonstrated four basic indicators regarding time, quality, labour cost and efficiency. On the other hand, Davarzani and Norrman (2015) demonstrated in the research that majority of researches pertain to mathematical models and simulation models within the picking area (Grosse et al. 2017). 


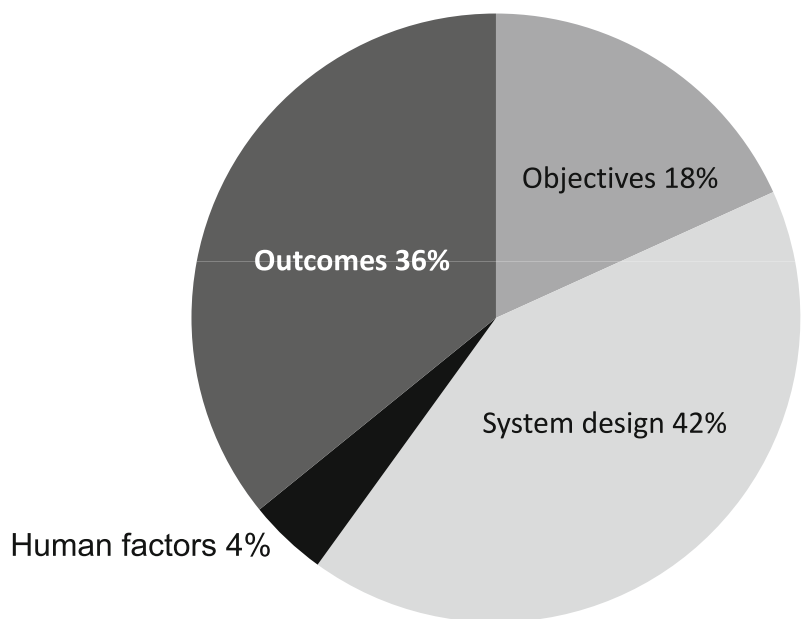

Fig. 1 Top mentioned recording units in each content category

$\mathrm{HF}$ aspects in the warehousing economy in relation to the picking phase, were formerly underlined by aforementioned Grosse et al. (2015). In the studies they selected 4 groups of factors: perceptual, psychical, physical and psychological, affecting the efficiency and health of the picking personnel.

Due to the influence of ergonomic aspects on the picking process, several authors have made researches on incorporating these aspects in decision-supporting models, in the field of picking (Boysen et al. 2015). This integration takes place in the area of goods assignment, which is important from the picking-planning scope of view.

However in 2017 research was undertaken in which was included the perception of working conditions and health problems by warehouse worker (Gajsek et al. 2017).

In 2018 Vujica Herzog et al. conducted research on the effects of using smart glasses on the comfort of users during order picking activities. Smart glasses were tested for $4 \mathrm{~h}$. Ophthalmologic tests were performed before and after use of smart glasses and the result this test showed that there were some statistically differences between test. The result of the performed ophthalmologic tests (visual acuity, contrast sensitivity, colour test) showed that of smart glasses for $4 \mathrm{~h}$ during work can cause scotomas and thus impairment in the visual field and vision.

When reassuming the above statements and with application of the Grosse et al. (2017) researches, HF aspects are insufficiently researched in the warehousing management, in the field of picking at mechanized warehouses, which is clearly demonstrated at Fig. 1. They reached only $4 \%$ of total topics that included the design and warehouse management. Moreover, when comparing total hits, it can be also concluded, that the literature on manual picking generally pertains to economic aspects, and ergonomic aspects is considered in a lesser degree. For example, ergonomics had only 177 hits in 186 papers, what is demonstrated in Table 1 (Grosse et al. 2017).

Since this study is focused on the problem of assortment allocation in the warehouse, a short description for the problem is required. 
Table 1 Results of the content analysis

\begin{tabular}{|c|c|c|c|}
\hline & Category & Framework component & Results of the content analysis \\
\hline \multirow[t]{5}{*}{1} & \multirow[t]{5}{*}{ Objectives } & Cost & 2009 \\
\hline & & Travel distance & 1220 \\
\hline & & Travel time & 901 \\
\hline & & Pick time & 694 \\
\hline & & Throughput time & 371 \\
\hline \multirow[t]{5}{*}{2} & \multirow[t]{5}{*}{ System design } & Batching & 4355 \\
\hline & & Route & 3450 \\
\hline & & Zone & 1923 \\
\hline & & Layout & 1728 \\
\hline & & Shape & 442 \\
\hline \multirow[t]{5}{*}{3} & \multirow[t]{5}{*}{ Human factors } & Learning & 470 \\
\hline & & Workload & 214 \\
\hline & & Ergonomic & 177 \\
\hline & & Physical & 176 \\
\hline & & Incentive & 161 \\
\hline \multirow[t]{5}{*}{4} & \multirow[t]{5}{*}{ Outcomes } & Time & 7507 \\
\hline & & Performance & 1999 \\
\hline & & Quality & 354 \\
\hline & & Error & 187 \\
\hline & & Efficiency & 172 \\
\hline
\end{tabular}

Source: development based on Grosse et al. (2017)

Products in the warehousing area can be randomly assigned to warehousing locations, or according to certain criteria (e.g. frequency, groups of recipients), which is referred to as dedicated attribution of locations. Both allocation methods have own advantages and disadvantages. The main advantage for random allocation of location is large exploitation of warehousing zone (Petersen 1997; Battini et al. 2016). In the case of dedicated location assignments, all items are allocated to fixed locations in the warehouse. A popular criterion for this type of warehousing method is turnover of products, where frequently ordered items are assigned to the places located closest to the release area (Rao and Adil 2013; Battini et al. 2016). An advantage of this method is shortened time required for searching goods in the warehouse (Grosse and Glock 2013, 2015). However, it should be noted that demand for a particular product changes in time, thus allocation of places according to this method requires allocation changes according to demand, what can increase operational costs and decrease efficiency (Grosse et al. 2013; Battini et al. 2016).

Several decision making problems such as fixing the cost of goods, profit for sellers are solved by the TP. Nowadays, in the competitive market scenario, minimizing the transportation cost in a business economy is one of the utmost important challenges (Maity et al. 2019). The uncertainty of supply and demand in TP's problems was taken into account in the research Maity et al. (2019) and Roy et al. (2017a). 
Roy et al. (2017a) formulated the mathematical model of Two-Stage Multi-Objective Transportation Problem (MOTP) where allowed for the supply and demand contrants. In this way the solution of the MOTP under these goals through RMCGP provided a technique for multi-objective decision (Roy et al. 2017a). Also considered fuzzy multiple-choice goals to the objective functions of the MOTP and Fuzzy Multi-Choice Goal Programming to properly select goals for the objective function of the proposed MOTP (Maity et al. 2016). Another important notation is to incorporate the goal preferences of the decision maker. The authors have proposed to solve multi-choice multi-objective transportation problem by employing the conic scalarization approach with less number of variables and with minimum computational burden (Roy et al. 2017b). Whereas Das et al. (2019) they studied the solid transportation-p-facility location problem (ST-p-FLP). They presented a generalization of the classical STP in which location facility sites are sought so that the total transportation cost by means of conveyances from existing facility sites to potential facility sites will be minimized. They developed two heuristic and the heuristics were evaluated by an application example. Also a multi-objective fixed-charge transportation problem (MOFCTP) was considered in which the parameters of the objective functions are random rough variables, while the supply and the demand parameters are rough variables (Roy et al. 2018).

A method also can be found, that combines the method of permanent and random storage locations. In this case, all products are allocated to many different classes (e.g. according to demand) and each class is allocated to a specific area in the warehousing zone (area A, area B, etc.). In this case of warehouse, the most-demanded goods are allocated in the area, that is closest to the release/picking zone (Chackelson et al. 2013; Battini et al. 2015, 2016). Another version of this method is assignment of locations for goods, that are often jointly ordered. In this situation, the jointly ordered goods are assigned to the places located close to each other (Chuang et al. 2012; Battini et al. 2016).

Warehousing economy is generally discussed in the presented literature, where it focuses on development of methods decreasing transportation time and distance, therefore reducing the order picking time. Whereas, the goals related to ergonomics were omitted in this literature. The analysis for this literature primarily demonstrated support for managerial decisions related to financial efficiency and warehouse performance.

\section{Research and discussion}

Analysis for the assortment allocation problem in the warehouse with multiple corridors was analysed in the researches. For simplicity reasons, it was assumed that the collection and release zone is located next to one warehouse wall (hereinafter referred to as the I/O point), which means that the bag-type warehouse is analysed. The assortment is classified according to the ABC model and its size and shape is normalised.

The swarm optimization algorithm was used in the analysis (Karaboga 2005; Tereshko and Loengarov 2005). The software was made in C++, and the corresponding UML class diagram is illustrated in Fig. 2. 


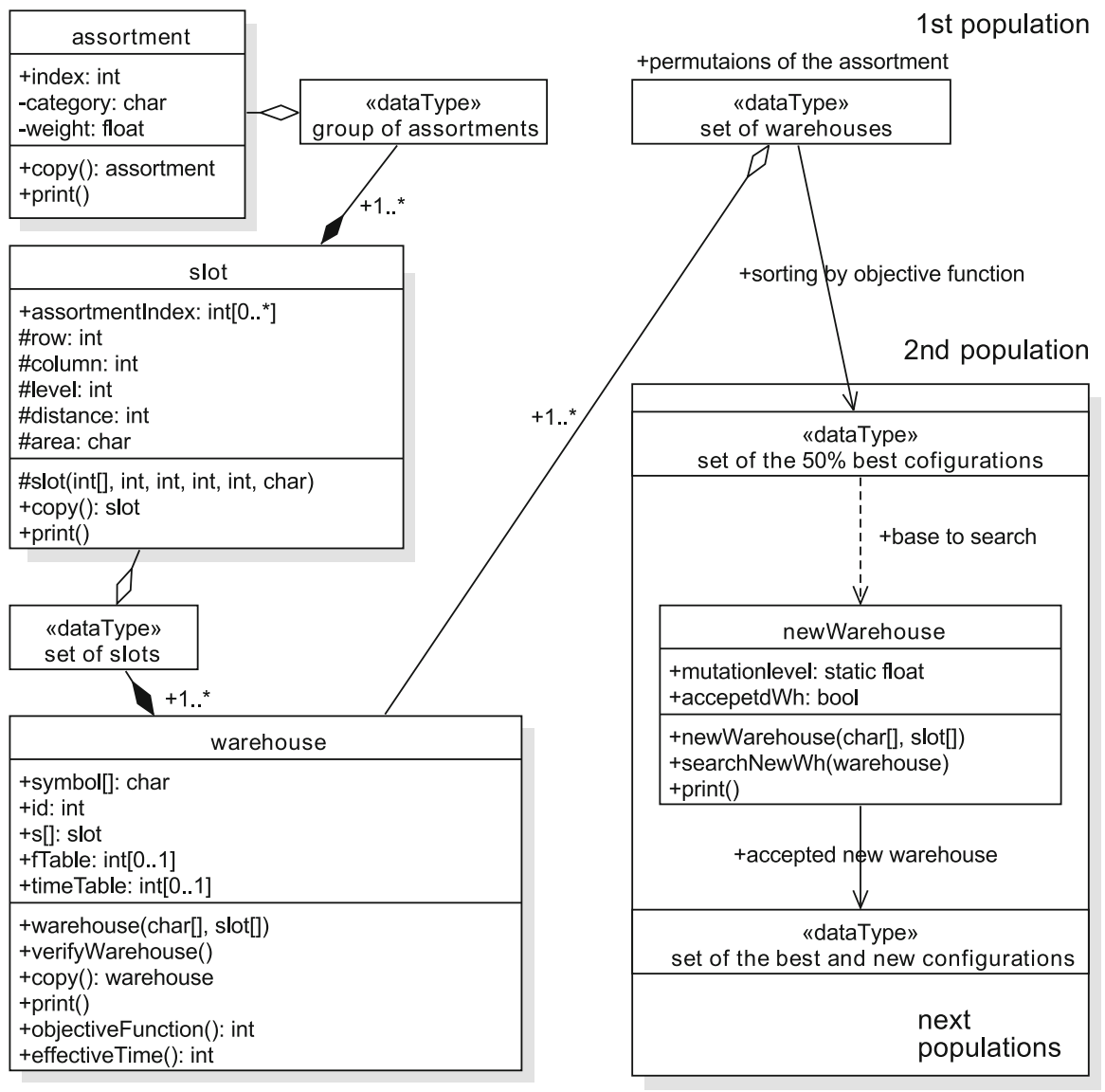

Fig. 2 The UML class diagram of the algorithm. In the phase (1) of the simulation the associated objects: assortment, slot, warehouse are created, while during phase (2) the hundreds of warehouse copies with permutations of the assortment are sorted by objective function and the best of them are mutated as newWarehouse objects in the next populations

The simulation is divided into two phases: (1) creating the initial configuration of a warehouse, including a completely random set of warehouse permutations, as the so-called initial population and (2) the warehouse optimization phase, as modification of the best representatives in the subsequent populations.

In the phase (1) the assortment is selected. The warehouse is constructed as several shelf areas composed of levels, columns and sockets. The algorithm assigns the assortment to specific sockets, with possibility of multiple selection of the same assortment. The specified configuration creates the warehouse. Next, the simulation is based on random mutation of assortment locations (relocations to empty spaces, replacement of locations) within many variants of warehouses. In this way, an output set consisting of hundreds of warehouse copies with the same assortment is created.

The phase (2) is based on application of the selection mechanism, by selection of $50 \%$ the best configurations, based on the objective function. Better configurations are 
searched with means of the controlled (subject to the assessment), gradual mutation of warehouses. It is so-called local optimization, defined as a neighbourhood search. In this way, another population composed of the best and improved sequences is created.

Simulations are completed for the generation, when no better values for the objective function are not found or changes are below the expected accuracy criterion.

The objective function is described with two components:

- square, considering correlation between the assortment (from various product groups),

- linear, depending on allocation and type (e.g. weight) for an individual assortment:

$$
\min \rightarrow f=\sum_{i=1}^{N} \sum_{j=1}^{N} \sum_{p=1}^{N} \sum_{q=1}^{N} S_{i j} L_{p q} X_{i p} X_{j q}+\sum_{i=1}^{N} \sum_{p=1}^{N} C_{i p} X_{i p}
$$

where $L_{p q}$-distance for a unit of goods from the $p$ location to the $q$ location, $S_{i j}$-correlation coefficient between the $i$ and $j$ goods, $C_{i p}$-transportation cost of $i$ goods at $p$ location from I/O point, $X_{i p}, X_{j q}$-decision variables (0/1); location of the $i$ and $j$ goods $(i, j=1,2, \ldots, N)$, respectively at the $p$ and $q$ location $(p, q=1,2, \ldots, N)$.

The square factor describes the cost of relative allocation of goods, as a result of goods relationship within a category, whereas linear factor expresses transportation cost for goods to the warehousing location. Detailed schema of the calculations of both terms are shown on Fig. 3.

Variability of individual objective function components is easily illustrated by a simple example (Fig. 4). Let analyse the set comprised of three warehouse sockets, where products are allocated: two from A category and one from B. Variants (i) and (ii) differ with $\mathrm{A}$ and $\mathrm{B}$ locations, that have shifted locations, with constant location of other element from the A group (position'1').

Let the product correlations amount to $S_{A A}=40, S_{A B}=3$, distances $L_{12}=1, L_{13}=$ $11, L_{23}=10$ and transportation costs to the socket are $C_{A 1}=20, C_{A 2}=18, C_{A 3}=36$ and $C_{B 2}=6, C_{B 3}=12$ (the cost depends on distance and weight of the product A and B).

The objective function in the case of (i) is given by:

$$
f_{(i)}=S_{A B} L_{12}+S_{A A} L_{13}+S_{A B} L_{23}+C_{A 1}+C_{B 2}+C_{A 3}=473+62=535
$$

while in the case (ii):

$$
f_{(i i)}=S_{A A} L_{12}+S_{A B} L_{13}+S_{A B} L_{23}+C_{A 1}+C_{A 2}+C_{B 3}=103+50=153
$$

The square factor of the $f$ objective function in the case (i) amounts to 473 , whereas in (ii) to 103, the linear factor are equal 62 and 50, respectively. Total sum of both subtracts in the cases (i) and (ii) are 535 and 153, respectively. The example demonstrates that shifting only two products with locations can imply a considerable difference in the objective function.

Minimization of the objective function conducted on the hundreds of trials produced optimal configuration of variable assortment allocation, for which articles in the same 


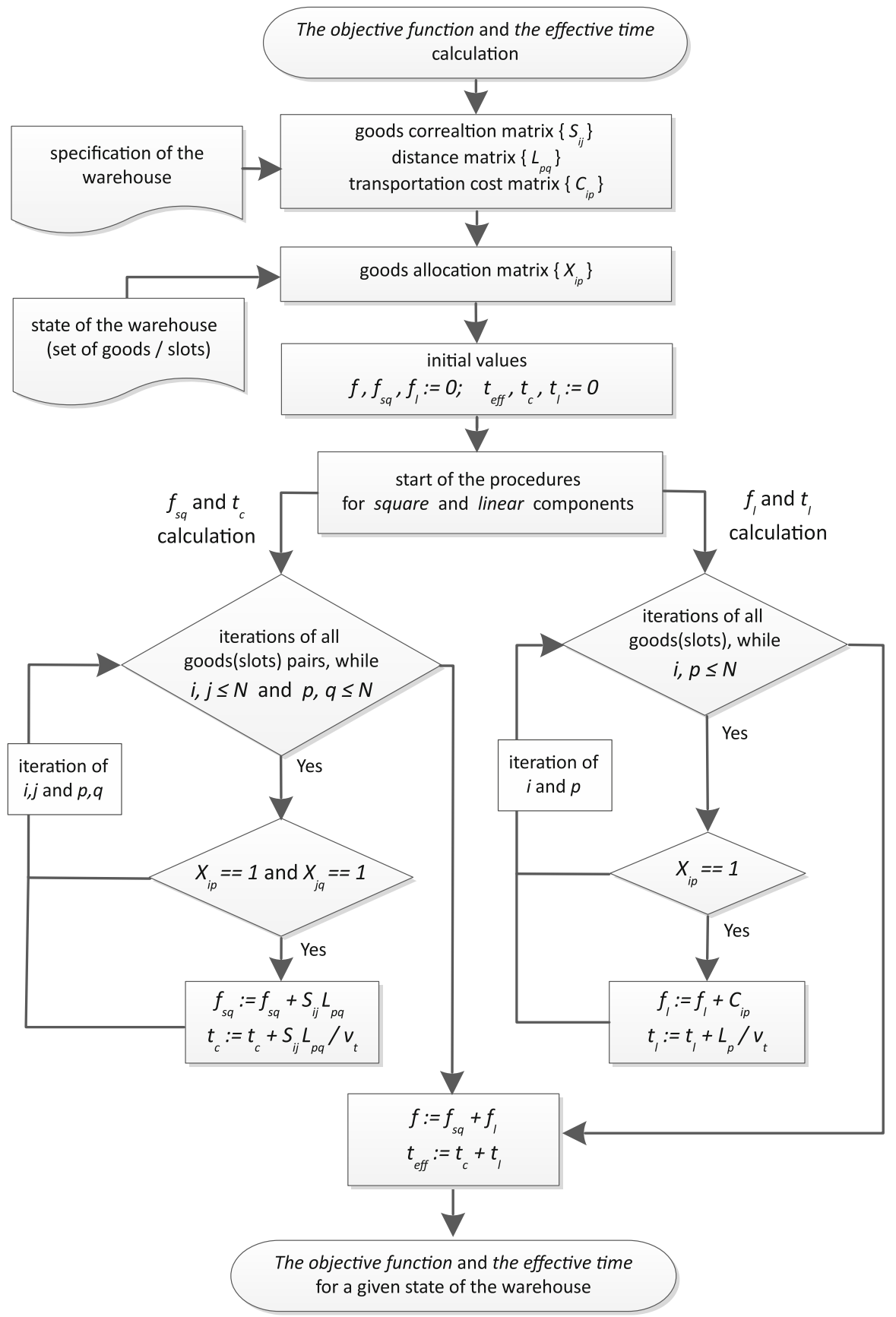

Fig. 3 Calculation schema for the objective function and the effective warehousing time 
(i)

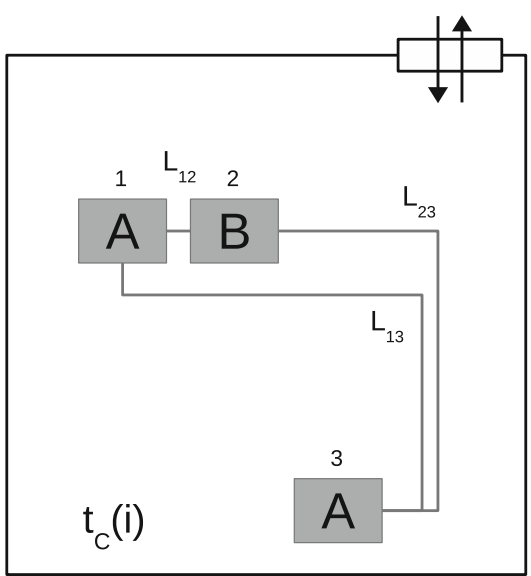

(ii)

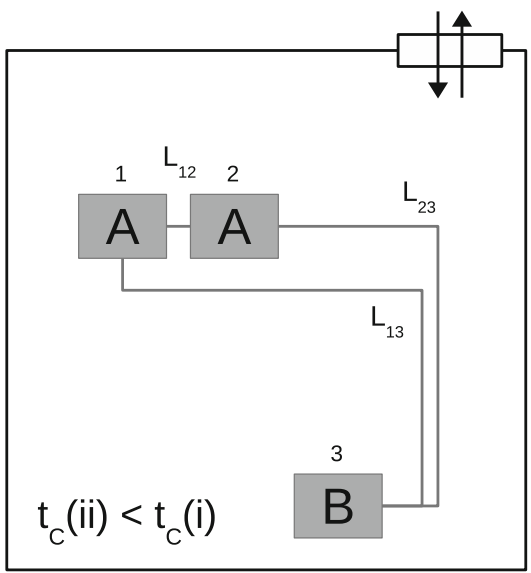

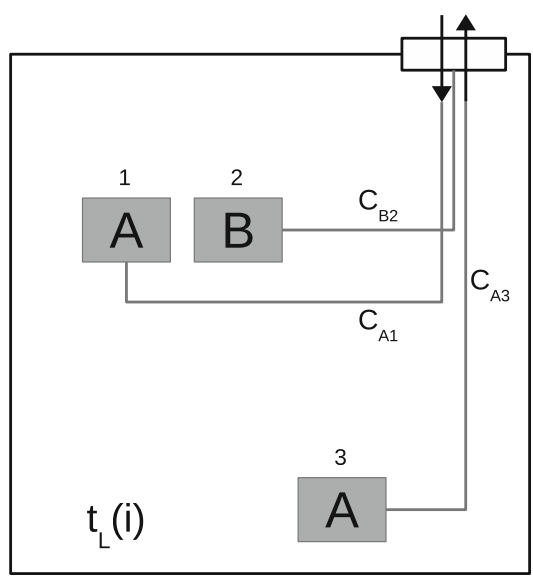

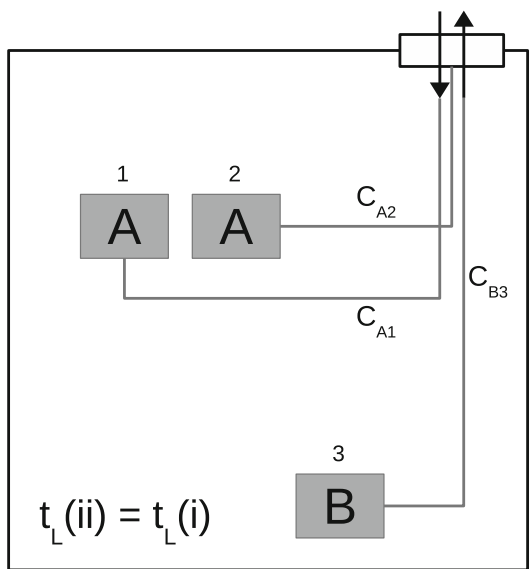

Fig. 4 Warehouse diagram including 3 products for two location versions (i)/(ii). Calculations of the square and the linear terms are illustrated on the left- and right side, respectively

category are stored as close to each other as possible (as a result of minimised square factor) and closest to the entrance to the warehouse, with leaving a free warehouse space at the farthest locations (with regard to the minimization of linear factor).

The question arises, whether the optimal configuration is also the best one, in terms of ergonomics of work? The answer is not obvious. However, we can assess the impact of variable allocation of goods on time-consumption and complexity of the warehouseman's work, with support of simulation.

Fatigue of an employee generally results from the work related to transportation of goods (with means of a fork-lift), that determines physical factor. On the other hand, complexity of the picking process (due to its mutual allocation in the warehouse) affects the comfort of work, which is directly related to the perceptual factor. Unfortunately, psychical factor is difficult in direct and quantitative estimation. 
The research results have quantitative form, because statistical analysis can be made with consideration to vast number of obtained warehouse configurations, and the level of cost optimisation correlation and the selected factors related to the ergonomics of warehouseman work can be determined.

An important measurement parameter is time for making a particular task (majorly layout of goods and picking potential orders, without regard to office work of a warehousemen). Similarly to the case of warehouse costs determination, two components are independently considered here: linear and square.

The first is related to delivery of the entire assortment to the respective warehouse locations. On the basis of product layout, a path followed by a forklift in the course of delivery of goods to the warehouse may be determined, and when considering its speed, labour time for each random configuration can be determined.

The second component describes the process of picking all goods in a warehouse, that is the sum of forklift courses, with probability proportional to the constant goodsto-goods correlation. When knowing distance between the goods, we can determine a potential distance travelled by forklift with a certain weight for each course and determine the effective labour time at the goods release stage, similarly to the former case.

In both components we omit handling time, which has a constant value for all configurations (it only depends on the number of assortment and distribution of sockets, that are constant simulation parameters), therefore it does not affect the variability of labour time.

Let's try to express it quantitatively. Let $v_{t}$ be the mean velocity of the means of transport (constant in the simulation, with irrelevant value when applying normalisation of results). Let define two time-dependent quantities:

- $t_{c}$, configuration component (picking of goods): time calculated as the sum of distance for all locations of the goods, in relation to each other, with the goods-to-goods correlation weight, divided by $v_{t}$. The weighting factor plays an analogous role here, similarly to the square part in the objective function, because it prefers organised configurations in relation to product groups.

- $t_{l}$, linear component (delivery of goods): time calculated as the sum of all distances $L_{p}$ for occupied sockets $\left(X_{p}=1\right)$ from $I / O$, divided by $v_{t}$,

The effective warehousing time $t_{\text {eff }}$ is defined as the sum of $t_{c}$ and $t_{l}$ :

$$
t_{e f f}=\sum_{i=1}^{N} \sum_{j=1}^{N} \sum_{p=1}^{N} \sum_{q=1}^{N} S_{i j} L_{p q} / v_{t} X_{i p} X_{j q}+\sum_{p=1}^{N} L_{p} v_{t} X_{p}
$$

For a given configuration, $t_{\text {eff }}$ values express a certain maximized service time value in the warehouse (including delivery and any possible picking of goods). It is strictly stochastic but it allows for quantitative description of real time-consumptionvariability problem during warehouse operations, as a function of variable allocation of goods.

The simulation was performed for dozens of initial samples (covering various sets of assortment) and thousands of derivative configurations were generated, as next generations. The observed results are convergent and lead to joint conclusions. 
In all simulations, a high variation in $t_{c}$ picking time with regard to the selected configuration was observed. At the same time, it was found that the $t_{l}$ linear factor only depends on locations of random sockets and does not change in the final simulation phase, when the sockets closer to the warehouse exit are occupied (searching for a better configuration is generally based on replacing the assortment locations). In the simplest situation, it is illustrated in Fig. 4-the picking time $t_{c}$ is clearly lower for the situation, in which two correlated $A-A$ articles are close to each other, while delivery time $t_{l}$ is the same for both assortment location versions.

Therefore, it is possible to make a thesis, that a change in the warehouseman's effective labour time mainly depends on configuration of goods allocation, whereas the determined layout of warehouse sockets produces a constant labour time component related to delivery (within a settled amount of assortment).

Figure 5 demonstrates the sequences of the most favourable objective function values for two consecutive generations and the corresponding $t_{\text {eff }}$ time values (both values are normalized with regard to initial configuration). What can be seen, $t_{\text {eff }}$ time values are not strictly proportional to the objective function for individual configurations. This means that there is no direct relationship between the warehousing costs and the warehousing time (which is only one parameter of such costs from many, according to knowledge).

However, we have noted that there is a clear statistical dependency for the presented results.

First of all, we can see a common trend for variability in both values, within the same generation. The correlation coefficient of the objective function $f$ versus $t_{\text {eff }}$ for 1 generation is 0.65 , whereas for 2 generation it is already 0.83 (the correlation increases in the subsequent generations due to the smaller spread of results, because warehousing configurations are searched in the surrounding of the best solutions).

In addition, similar trends for the changes in both values in the subsequent generations can be observed. We observe a proportional reduction in their average values, and the calculated factor was almost identical for both values and amounted to 0.96 (average 1 generation results/average 2 generation results).

In the graph of effective warehousing time, we can see a decrease in timeconsumption for warehouse operation at the level of $8-10 \%$. This means that the service employees daily labour intensity indicator (defined as: daily flow of goods $\mathrm{x}$ service cycle execution time/number of goods serviced in 1 cycle) decreases due to the service cycle execution time, what increases the labour comfort at the position of warehouseman. This influences the improvement of the physical factor. A shorter order execution time also beneficially influences on the execution of planned schedule, what improves the psychical factor, in turn.

On the other hand, the optimal allocation of goods (the objective function is reduced with about 5-7\%), means easier operation of the forklift staff in the order picking process, what improves the ergonomics of work at this position. For these reasons, the warehouseman's labour intensity indicator (defined as: volume of warehouse turnover/number of hours worked by warehousemen) will increase, what directly results from the improvement in the perceptual factor when pursuing orders. However, an increase in this indicator cannot be seen as an additional workload, it is only the result of better organization of work. 

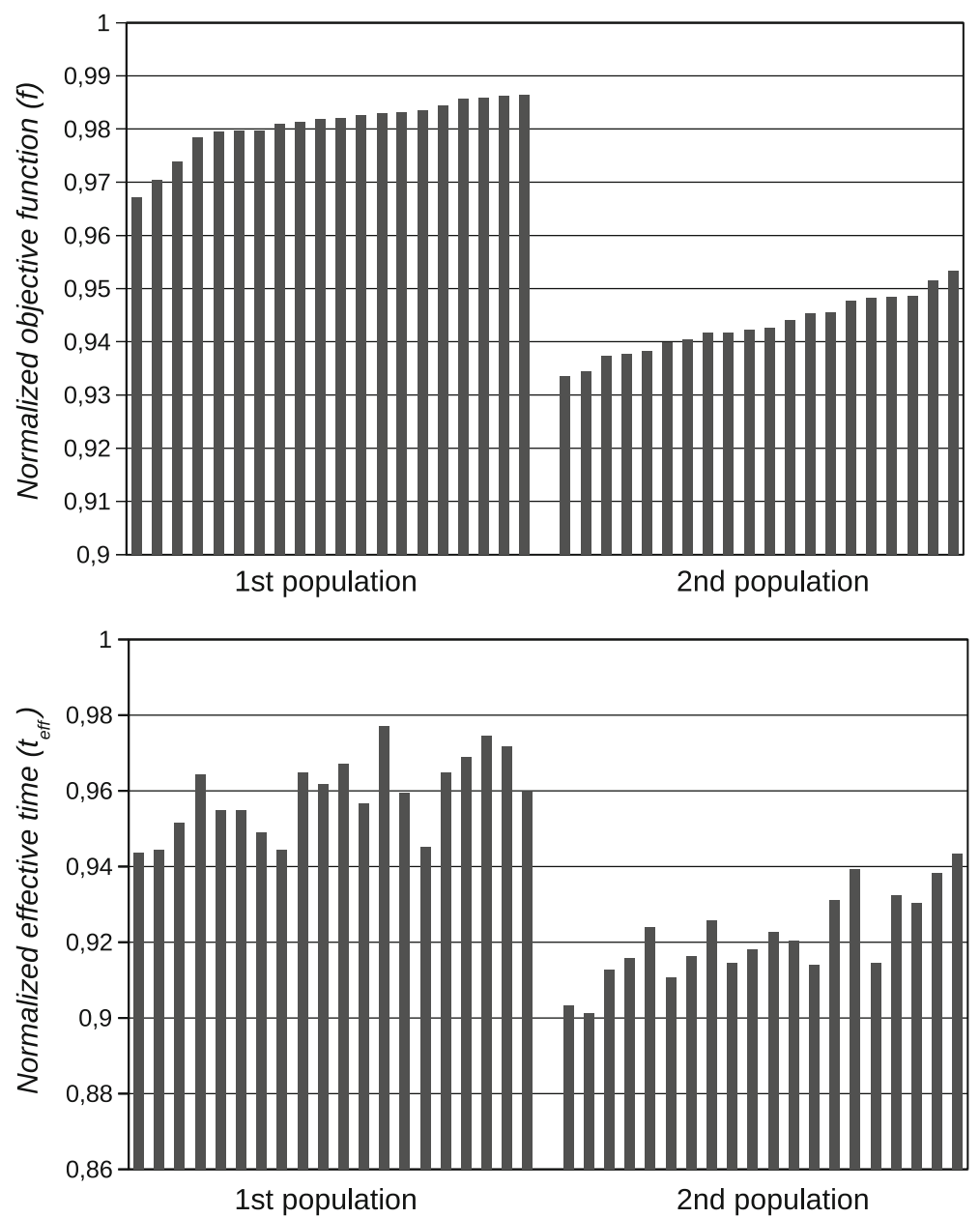

Fig. 5 Normalized objective function $f$ values and the corresponding normalized effective warehousing time $t_{\text {eff }}$ values for the 20-best configurations within 2 generations

\section{Summary}

According to the previous studies, the impact of organizational changes in the warehouse on the ergonomics of operators' work has not been fully recognized. This particularly pertains to the innovative solutions in the field of the assortment storage and its optimization. This aspect becomes important in the scope of demographic changes (aging of employees and difficulties in acquiring new personnel) and implementation of the industry 4.0. Companies pay more and more attention to the continuous improvements in warehousing, through implementation of new technologies, digitization oriented on keeping the high service level and competitiveness.

Results of this study demonstrate that support for warehouse services with an appropriate optimisation system for assortment allocation in the warehouse, with respect to 
warehouse costs, also (statistically) generates an improvement in the warehouseman's quality of work, in physical terms. The simulation model was used for this purpose. A direct correlation between the cost optimisation and the statistical time-consumption of labour in the field of picking the goods was also demonstrated. It can have any impact on lower employee fatigue.

In turn, a closer allocation of goods from the same commodity group makes the perception of assortment location easier, during the picking process. The above conclusions obtained from the study on the simulation model can be the basic for verification in real conditions of the warehouse. The issue of the psyche and fatigue of the employee was not possible, because these areas will be the subject of further research.

The studies presented above demonstrate that there are promising methods for implementation of warehousing management solutions related to the improvement in human factors. This is all the more important, because warehouse managers make much efforts in technological organization and planning procedures for allocation and picking the assortment in the warehouse, in order to increase the efficiency of subordinate employees.

Open Access This article is distributed under the terms of the Creative Commons Attribution 4.0 International License (http://creativecommons.org/licenses/by/4.0/), which permits unrestricted use, distribution, and reproduction in any medium, provided you give appropriate credit to the original author(s) and the source, provide a link to the Creative Commons license, and indicate if changes were made.

\section{References}

Baker P, Perotti S (2008) UK Warehouse Benchmarking report. Cranfield School of Management, Cranfield University, Cranfield

Battini D, Calzavara M, Persona A, Sgarbossa F (2015) Order picking system design: the storage assignment and travel distance estimation (SA\&TDE) joint method. Int J Prod Res 53(4):1077-1093

Battini D, Glock ChH, Grosse EH, Persona A, Sgarbossa F (2016) Human energy expenditure in order picking storage assignment: a bi-objective method. Comput Ind Eng 94:147-157

Boysen N, Emde S, Hoeck M, Kauderer M (2015) Part logistics in the automotive industry: decision problems, literature review and research agenda. Eur J Oper Res 242(1):107-120

Chackelson C, Errasti A, Ciprés D, Lahoz F (2013) Evaluating order picking performance trade-offs by configuring main operating strategies in a retail distributor: a design of experiments approach. Int $\mathbf{J}$ Prod Res 51(20):6097-6109

Chuang Y-F, Lee H-T, Laih Y-C (2012) Item-associated cluster assignment model on storage allocation problems. Comput Ind Eng 63(4):1171-1177

Das SK, Roy SK, Weber G-W (2019) Heuristic approaches for solid transportation-p-facility location problem. Central Eur J Oper Res. https://doi.org/10.1007/s10100-019-00610-7

Davarzani H, Norrman A (2015) Toward a relevant agenda for warehousing research: literature review and practitioners input. Logist Res 8(1):1-18

De Koster R, Le-Duc T, Roodbergen KJ (2007) Design and control of warehouse order picking: a literature review. Eur J Oper Res 182(2):481-501

Frazelle EA (2002) World-class warehousing and material handling. McGraw-Hill, New York

Gajsek B, Vujica Herzog N, Butlewski M, Durkic G (2017) Research opportunity: incorporation of human factors in order picking system models. Sci J Poznan Univ Technol Ser Organ Manag 72:45-61

Glock ChH, Grosse EH, Neumann WP, Sgarbossa F (2017) Editorial: human factors n industrial and logistic system design. Comput Ind Eng 111(2017):463-466

Gong Y, de Koster RB (2011) A review on stochastic models and analysis of warehouse operations. Logist Res 3(4):191-205 
Grosse EH, Glock CH (2013) An experimental investigation of learning effects in order picking systems. J Manuf Technol Manag 24(6):850-872

Grosse EH, Glock CH (2015) The effect of worker learning on manual order picking processes. Int J Prod Econ 170(Part C):882-890

Grosse EH, Glock CH, Jaber MY (2013) The effect of worker learning and forgetting on storage reassignment decisions on order picking systems. Comput Ind Eng 66(4):653-662

Grosse EH, Glock CH, Jaber MY, Neumann WP (2015) Incorporating human factors in order picking planning model: framework and research opportunities. Int J Prod Res 54(3):695-717

Grosse EH, Glock CH, Neumann WP (2017) Human factors in order picking: a content analysis of the literature. Int J Prod Res 55(5):1260-1276

Gu J, Goetschalckx M, McGinnis LF (2007) Research on warehouse operation: a comprehensive review. Eur J Oper Res 177(1):1-21

Gu J, Goetschalckx M, McGinnis LF (2010) Research on warehouse design and performance evaluation: a comprehensive review. Eur J Oper Res 203(3):539-549

Jasiulewicz-Kaczmarek M, Saniuk A (2015) Human factor in sustainable manufacturing. In: Antona M, Stephanidis C (eds) Universal access in human-computer interaction access to the human environment and culture, vol 9178. LNCS, Mexico City, pp 444-455

Karaboga D (2005) An idea based on honey bee swarm for numerical optimization. Technical Report TR06, Erciyes University, Engineering Faculty, Computer Engineering Department

Maity G, Roy SK, Verdegay JL (2016) Multi-objective transportation problem with cost reliability under uncertain environment. Int J Comput Intell Syst 9(5):839-849

Maity G, Mardanya D, Roy SK, Weber G-W (2019) A New approach for solving dual-hesitant fuzzy transportation problem with restrictions. Sadhana 44:75

Napolitano M (2012) 2012 Warehouse/DC operations survey: mixed signals. Mod Mater Handl 51(11):48-56

Pervin M, Roy SK, Weber G-W (2018) Analysis of inventory control model with shortage under timedependent demand and time-varying holding cost including stochastic deterioration. Ann Oper Res 260:437-460

Petersen CG (1997) An evaluation of order picking routeing policies. Int J Oper Prod Manag 17(11):1098-1111

Rao SS, Adil GK (2013) Class-based storage with exact S-shaped traversal routeing in low-level picker-topart systems. Int J Prod Res 51(16):4979-4996

Report DHL (2018) Robotics in logistics. A DPDHL perspective on implications and use cases for the logistics industry, report from www.dhl.com/robots. Accessed 21 Sep 2018

Report Automation in warehouse from www.logistyka.net.pl/aktualnosci/raporty-i-analizy/item/. Accessed 22 Aug 2018

Richards G (2014) Warehouse management: a complete guide to improving efficiency and minimizing costs in the modern warehouse. Kogan Page, London

Rouwenhorst B, Reuter B, Stockrahm V, van Houtum GJ, Mantel RJ, Zijm WH (2000) Warehouse design and control: framework and literature review. Eur J Oper Res 122(3):515-533

Roy SK, Maity G, Weber G-W (2017a) Multi-objective two-stage grey transportation problem using utility function with goals. CEJOR 25(2):417-439

Roy SK, Maity G, Weber G-W, Alparslan Gök SZ (2017b) Conic scalarization approach to solve multichoice multi-objective transportation problem with interval goal. Ann Oper Res 253:599-620

Roy SK, Midya S, Yu VF (2018) Multi-objective fixed-charge transportation problem with random rough variables. Int J Uncertain Fuzziness Knowl-Based Syst 26(6):971-996

Statistics Poland (GUS), Accident Report at work in the first half of 2018 - preliminary data report from http://stat.gov.pl/obszary-tematyczne/rynek-pracy/warunki-pracy-wypadki-przy-pracy/. Accessed 20 Sep 2018

Staudt FH, Alpan G, Di Mascolo M, Rodriguez CMT (2015) Warehouse performance measurement: a literature review. Int J Prod Res 53(18):5524-5544

Tereshko V, Loengarov A (2005) Collective decision-making in honey bee foraging dynamics, computing and information systems, vol 9(3). University of the West of Scotland, Glasgow, pp 1-7

Tompkins JA, White YA, Bozer EH, Tanchoco JMA (2010) Facilities planning, 4th edn. Wiley, Hoboken

Van den Berg JP (1999) A literature survey on planning and control of warehousing systems. IIE Trans 31(8):751-762 
Vujica Herzog N, Buchmeister B, Beharic A, Gajsek B (2018) Visual and optometric issues with smart glasses in Industry 4.0 working environment. Adv Prod Eng Manag 13(4):417-428

Publisher's Note Springer Nature remains neutral with regard to jurisdictional claims in published maps and institutional affiliations. 